Macedonian Pharmaceutical Bulletin, 66 (Suppl 1) 197 - 198 (2020)

Online ISSN 1857 - 8969

UDC: $615.12: 340.13(497.7)$

DOI: 10.33320/maced.pharm.bull.2020.66.03.098

Short communication

\title{
Community pharmacies in North Macedonia - legal status
}

\author{
Bistra Angelovska*, Elena Drakalska, Dijana Miceva \\ Faculty of Medical Sciences ,University “Goce Delcev”-Stip, Krste Misirkov 10-A , 2000 Stip, N. Macedonia
}

Introduction

Typically for the entire pharmaceutical system is complex legislation. The structure of drug regulation needs to be continually evolved to respond appropriately to the growing challenges of society.

The population served by one pharmacy varies from 18,000 in Denmark to 1,000 in Greece. In the Republic of North Macedonia in 2012 one pharmacy serves around 3,000 inhabitants, which has been established as the maximum number of pharmacies in accordance with the Regulation of Health Institution Network. According to current published population and number of pharmacies, in 2019 one pharmacy serves about 1800 inhabitants.

The purpose of this paper is to review and analyze the regulation related to public pharmacies voted in the last decade and to see the current legal status, with a discussion of specific solutions and suggestions for possible improvement.

\section{Materials and methods}

The laws, bylaws, regulation and decisions from 1992 to 2020 were used to regulate the operation of public pharmacies.

The materials were reviewed and have been chronologically analyzed and sorted by impact on the general status of pharmacies. A comparative method and a compilation method were used.

\section{Results and discussion}

Retailing of medicines in the Republic of North Macedonia is carried out at primary health care institutions - pharmacies and hospital pharmacies within the hospital health institutions. The authorization for doing business is regulated by the Law on Medicines and Medical Supplies (as Retail Trade) and the Law on Health Care (as a health care institution), and in accordance with the bylaws of the Law on Health Care. The Law on Medicines and Medical Devices from 2007 to 2019 has 17 amendments and additions. The pharmacy is a health institution and the establishment and activity of the pharmacy is carried out in accordance with the Law on Medicines and Medical Devices and the Law on Health Care, and the approval for performing the activity of the pharmacy is issued by the Minister of Health for an indefinite period. It has public service status, which is not always respected when issuing approvals.

Amendment to 2013: categorization of pharmacies in terms of space, equipment and staff refers to settlements in rural areas and goes into the competence of the Ministry of Health (MOH).

Amendment to 2014: Pharmacy founder can only be a pharmacist (abolished by Constitutional Court Decision); allowed retailing of drugs outside the pharmacy; owners who own more than two pharmacies are required to open a pharmacy in a rural area.

Amendment to 2015: changed the name of the law to the Law on Medicines and Medical Supplies; stricter penalties for the sale of a drug classified as a prescription drug; a distance of at least 100 meters

\footnotetext{
* bistra.angelovska@ugd.edu.mk
} 
from one pharmacy to another for low density populated areas; permitted retail supply of prescription drugs at the store or at a gas station; The Director of the Agency shall prescribe the procedure, conditions and manner of obtaining a retail marketing authorization by a by-law which has not yet been voted.

From 2010 to 2018 , three changes were made to the implementation of act to have a pharmacist in each shift.

From the Health Care Law in 1991 have been defines the pharmaceutical activity as part of the health activity, the pharmacist as a health worker and the pharmacy as a health institution. The competent authority for approval of activity is the Ministry of health. The authorization is issued in accordance with the Health Care Law and the Law on Medicines and Medical Devices, and the closer conditions regarding space, equipment and staff are regulated by a Rulebook voted in 1992 and amended in 2005 .

Amendment to 2004: privatization of the pharmacy activity. The profile of the founder / owner of the pharmacy is not specified, but the carrier must be a pharmacist.

In 2012, a new one law was voted, and that one is undergoing 18 changes and additions by 2019 . The pharmacy is regulated identically as in the old law.

In the new Rulebook on space equipment and staff voted in 2013 the requirements are almost identical to those prescribed in the Rulebook from 1992.

The list of health services that can be provided at a pharmacy is based on the definition of a pharmacy from 1977 year. It was adopted at the end of 2013 and has not been updated nor adapted to the contemporary needs of the health system and patients

With the Methodology on the Formation of Unique Drug Prices (2011), a by-law of the Law on Medicines and Medical Devices, the price of the service is marginal, scalable and regressive depending on the wholesale price. With the methodology from 2019 the pharmacy service is still calculated as a margin, not as a health service.

The Law on Health Insurance has 45 amendments from 2000 to 2019. At the pharmacy, drugs are issued from the Fund's List of Medicines at Reference Prices that are different from the unique prices adopted under the Pricing Methodology. The price of the pharmacy service is unchanged from 2008 to 2019 and is in a fixed amount, scalable and regressive depending on the reference price, on average around 15.00 denars per issued drug. Amendment to 28.10.2019 - the service is calculated as $18 \%$ margin on the invoiced medicines at a reference price, but not more than 180.00 denars, on average around 17.00 denars by prescription issued.

The cost of the service should not be related to the cost of the drug, but to the service provided. It is necessary to revise the List of services provided at the pharmacy and standardize it according to the resources consumed (material, human by qualification and time) to obtain a realistic cost of service, to improve the quality and the final outcome of therapy.

\section{Conclusion}

Frequent and inconsistent amendments to laws and bylaws, often with inadequate changes and interference with the powers to implement them, untimely voting of bylaws and poor coordination between laws regulating the sector create confusion and make it difficult to implement. None of the changes made to the implementing laws and bylaws penetrates the core of the business and does not improve the status of pharmacies. This prevents the development of modern practices such as those in developed countries that have proven to save financial resources on funds, citizens and society, while improving the outcome of therapy and public health. It is necessary to vote a Law on Pharmacy, to redefine the activity and list of services, to vote a unique methodology for pricing and to change the way of payment of the pharmaceutical service according to the service rendered and the resources.

\section{References}

Law on Medicinal Products and Medical Device (Off. Gazette 17/97, 106/2007 to 275/2019).

Law on Health Protection ("Off. Gazette 43/2012275/2019).

Law on Health Insurance (Off. Gazette 25/2000 275/2019).

Methodology on the Formation of Unique Drug Prices (Off. Gazette 156/11, 45/12).

Regulation of Health Institution Network (Off. Gazette $81 / 12$ ).

Rulebook on space equipment and staff for the establishment and operation of healthcare organizations (Off. Gazette 11/92, 30/05,91/13).

Maced. Pharm. Bull. 66 (Suppl 1) 197 - 198 (2020) 